\section{Easy Access IP: ahead of the game or easy way out?}

\section{By C. Simone Fishburn, Senior Editor}

As university technology transfer offices grapple with how best to commercialize their discoveries, about 25 international universities are turning to Easy Access IP, a strategy to give patented inventions away for free. Supporters argue that giving away IP attracts potential investors, while some non-adopter technology transfer office heads think companies will only be attracted by well-fleshed-out legal agreements.

At the heart of the debate is an issue technology transfer offices (TTOs) and other stakeholders in translational research have talked about for years-the inefficiency and expense associated with licensing university patents.

Earlier this year, the Brookings Institution released a report that helped quantify the problem. The report looked at numbers from 155 TTOs that are members of the Association of University Technology Managers and found that less than $13 \%$ of universities generate enough revenue from licensing deals to cover their operating costs. ${ }^{1}$

The goal of Easy Access IP is to drive down those expenses. Kevin Cullen pioneered the strategy in 2010 when he was at the University of Glasgow and found that the cost of
"The proportion of technologies with potential for a financial return to the university is very low. Easy Access IP is a logical model for unlocking the nonfinancial value of the majority of university-developed technologies."

-Kevin Cullen, NewSouth Innovations
Other TTO heads, including Tom Hockaday, think investing time and resources in more conventional licensing activities brings the most value to universities. Hockaday is managing director of Isis Innovation Ltd., the tech transfer unit of the University of Oxford.

"Doing proper commercial deals is the best way to attract financial investment because that way companies have the security that they are developing a product based on a strong legal agreement and solid IP," he said.

Cullen countered that traditional licensing deals only work about $5 \%$ of the time. "The problem is that this model has been shown not to work for the majority
"Doing proper commercial deals is the best way to attract financial investment because that way companies have the security that they are developing a product based on a strong legal agreement and solid IP."

-Tom Hockaday, Isis Innovation Ltd.
IP, and we need to find new ways of getting more of that $95 \%$ put to use to increase the relevance and usefulness of the research base," said.

He said that the experience at the University of New South Wales was that the financial cost of moving IP out of the university was less than the intangible benefits created by getting IP in the hands of industry once cumbersome and expensive contracts were out of the picture.

Such intangible advantages, he said, include the potential economic effects of companies creating products based on university IP, benefits to patients and other end users and enhancements to the university's reputation.

"The proportion of technologies with potential for a financial return to the university is very low. Easy Access IP is a logical model for unlocking the nonfinancial value of the majority of university-developed technologies," said Cullen.

supporting all the activities involved in licensing inventions was rarely matched by the revenues received.

Cullen is now CEO of NewSouth Innovations, the tech transfer arm of The University of New South Wales.

Easy Access IP differs from the standard TTO model of patenting and licensing for profit as many inventions as possible. Instead, a university still patents the invention, but it gives away the majorityoften up to about $95 \%$ - of its IP licenses for free, thus bypassing the high costs and lengthy negotiations that often prevent academic discoveries from being commercialized.

Deals require a one-page contract in which the licensor commits to perform some activity related to the invention within three years, agrees to acknowledge the university if the IP is successfully exploited and guarantees not to take action against the university for pursuing research in that area.
Hockaday said that he prefers a system such as the Isis Smart IP Scheme, which was set up to give small and medium enterprises (SMEs) greater flexibility and reduced risk by using a phased program to access university IP projects.

"We launched the Oxford Isis Smart IP Scheme a while ago to encourage IP uptake for SMEs. For many years we have offered simple evaluation agreements so a company can have a quick look at a technology to see if it wants to invest further," he said. "With Easy Access IP, universities invest in TTOs with a view to giving their research fruits away. We are investing in TTOs with a view to commercializing the research [and] transferring the technology to industry so that ideas from Oxford receive investment and may be converted into better products and services."

Cullen responded that his university "invests in the TTO to maximize the benefits deriving from our research; sometimes it is 


\section{ANALYSIS}

financial return, sometimes social or economic development benefits, sometimes reputational benefits. We are tasked with finding innovative ways of maximizing this mix of benefits."

Fishburn, C.S. SciBX 7(11); doi:10.1038/scibx.2014.303 Published online March 20, 2014

REFERENCES

1. Fishburn, C.S. SciBX 7(3); doi:10.1038/scibx.2014.77

\section{TRANSLATIONAL NOTES}

COMPANIES AND INSTITUTIONS MENTIONED

Association of University Technology Managers, Deerfield, III. Brookings Institution, Washington, D.C.

Isis Innovation Ltd., Oxford, U.K.

NewSouth Innovations, Sydney, New South Wales, Australia

University of Glasgow, Glasgow, U.K.

The University of New South Wales, Sydney, New South Wales, Australia

University of Oxford, Oxford, U.K. 